\title{
How Many Presentations Are Published as Full Papers?
}

\author{
Kyu Jin Chung, Jun Ho Lee, Yong Ha Kim, Tae Gon Kim, Ju Ho Ha \\ Department of Plastic and Reconstructive Surgery, Yeungnam University College of Medicine, Daegu, Korea
}

Background The publication rate of presentations at medical international meetings has ranged from $11 \%$ to $78 \%$ with an average of $45 \%$. To date, there are no studies about the final rate of publications at scientific meetings associated with plastic surgery from Korea. The present authors investigated the publication rate among the presentations at meetings associated with plastic surgery.

Methods The titles and authors of the abstracts from oral and poster presentations were collected from the program books of the Congress of the Korean Society of Plastic and Reconstructive Surgeons (CKSPRS) for 2005 to 2007 (58th-63rd). All of the abstracts presented were searched for using PubMed, KoreaMed, KMbase, and Google Scholar. The titles, key words from the titles, and the authors' names were then entered in database programs. The parameters reviewed included the publication rate, type of presentation including running time, affiliation, subspecialty, time to publication, and publication journal.

Results A total of 1,176 abstracts presented at the CKSPRS from 2005 to 2007 were evaluated. $38.7 \%$ of the abstracts, of which oral presentations accounted for $41.0 \%$ and poster presentations $34.8 \%$, were published as full papers. The mean time to publication was 15.04 months. Among journals of publication, the Journal of the Korean Society of Plastic and Reconstructive Surgeons was most used.

Conclusions Brilliant ideas and innovative approaches are being discussed at CKSPRS. The $38.7 \%$ publication rate found from this research appeared a bit lower than the average rate of medical meetings. If these valuable presentations are not available as full papers, the research would be a waste of time and effort.

Keywords Publications / Surgery / Plastic / Meeting abstracts

\author{
Correspondence: Jun Ho Lee \\ Department of Plastic and \\ Reconstructive Surgery, Yeungnam \\ University College of Medicine, 170 \\ Hyeonchung-ro, Nam-gu, Daegu \\ 705-717, Korea \\ Tel: +82-53-620-3480 \\ Fax: +82-53-626-0705 \\ E-mail: psjhlee@naver.com
}

This article was presented at the 69th Congress of the Korean Society of

Plastic and Reconstructive Surgeons on November 11-13, 2011 in Seoul, Korea.

No potential conflict of interest relevant to this article was reported.

\section{INTRODUCTION}

The scientific meeting is a key forum where researchers can share the results of studies with others, presenters can draw attention to their studies or can correct some errors, and attendees can obtain new information. Besides, these meetings play a role in creating hypotheses, provoking arguments, developing guidelines, and reaching agreement.

The presentations at medical meetings disclose some limitations due to the non-openness of medical societies as well as their transient characteristics. Abstracts are presented in a program book, and they display the results as well as the theoretical basis of studies. However, there are many abstracts where insufficient data is available to validate the results of studies. A peer- 
review process is therefore essential for recognizing the theoretical basis of studies and applying the results to clinical practice. This should eventually be followed by publication of the research in journals. Thus, researchers can share the information, reach an agreement on disputes, and obtain the latest updates on medical information. Furthermore, the rate of publication in medical journals can also be used to assess the level of relevant scientific meetings [1].

It has been known that the rate of publication ranges between $11 \%$ and $78 \%$ among abstracts that have been presented at a variety of medical meetings. In addition, it is generally known that its mean value is $45 \%$ and does not exceed 50\% [2]. Besides, it has also been determined that a lower rate of publication is associated with presenters who are chased by deadlines, most of them being residents or fellows; problems with authorship; and the difficulty of selecting the best journal for publication [3].

Many academic societies have therefore performed a continuous analysis of the final publications in their journals. Thus, they evaluate the quality of presented studies and encourage the authors to finally publish the manuscripts. To date, however, there have been no studies about the final rate of publication from medical meetings associated with plastic surgery in Korea.

Given the above background, we conducted this study to analyze the rate of final publication, the length of time elapsed until the manuscript was finally accepted for publication, and the journals that had published the abstracts presented in a poster session or a free communication at the Congress of the Korean Society of Plastic and Reconstructive Surgeons (CKSPRS).

\section{METHODS}

We collected abstracts by analyzing the program books published by the Korean Society of Plastic and Reconstructive Surgeons (KSPRS) from the 58th academic meeting held in 2005 to the $63 \mathrm{rd}$ in 2007 . We selected only abstracts that had been presented as a free communication or in a poster session. Thus we excluded those that had been presented in a symposium or a panel session, both of which have educational value or address special interests. We confirmed whether abstracts were published by searching the PubMed database (http://www.ncbi.nlm. nih.gov/PubMed/) and Google Scholar (http://www.scholar. google.co.kr/) for those published in overseas peer-reviewed journals, and the KoreaMed database (http://www.koreamed. org/SearchBasic.php) and the KMbase database (http://kmbase.medric.or.kr/) for those published in Korean journals until the date of August 31, 2011.

As methods for searching, we started with the name of the first authors enrolled in the studies and then searched for the initials of the first name and the full last name of the other co-authors. Then, we searched using the title of abstracts and the key words. Given that the affiliation of the authors of manuscripts presented at meetings and published in journals were identical, we additionally searched using their affiliations. This database search was performed by three independent investigators. In the end, we considered the manuscript to be published when we confirmed that one or more authors were identical and when there was consistency of conclusions between the abstract and full paper.

Presentations were classified according to their types (oral presentation or poster session), affiliations (teaching hospitals, private hospitals, or a combination of the two) and subspecialty areas. The oral presentations were sub-classified according to the running time of the presentation: three minutes and six minutes. The subspecialty areas in association with the presentations include basic, cosmetic, congenital anomaly, hand, trauma, and tumor subspecialties, which were identified from the program books. However, we deliberately did not use these subspecialty areas in classifying poster presentations because the academic societies had no classification of the poster presentations by subspecialty area. The period of the publication since the presentation was defined as the length of time elapsed between the month of presentation and that of publication. We excluded abstracts that had been published prior to the presentation in measuring time to publication. We also investigated the journals of publication. We measured the overall rate of publication, which was defined as the ratio of published abstracts to total ones. We also measured the differences according to the classification of presentations and the time to publication according to the journal.

Statistical analysis was performed using SPSS ver. 19.0 (IBM Co., Armonk, NY, USA), for which a Pearson's chi-squared test was used. A P-value of $<0.05$ was considered statistically significant.

\section{RESULTS}

In a total of six meetings that ranged between that held in the spring of 2005 and that held in the autumn of 2007, there were a total of 1,176 presentations made among the free communication and poster presentation sessions. Of these, a total of $455 \mathrm{ab}-$ stracts (38.7\%) were published. The rate of publication was the highest (42.9\%) from the 59th meeting and the lowest (35.6\%) from the 61 st one. There was no significant difference in the rate of publication among the meetings (Table 1$)(\mathrm{P}=0.749)$.

We also analyzed the rate of publication of manuscripts based on the type of presentation. This showed that the rate of publication was $41.0 \%(301 / 734)$ in oral presentations and $34.8 \%$ $(154 / 442)$ in poster sessions. These results suggest that the rate of publication was significantly higher in oral presentations 
than poster sessions $(\mathrm{P}=0.035)$. In addition, we also analyzed the rate of publication based on the running time of three or six minutes. This showed that it was $43.2 \%$ and $37.5 \%$, respectively, but the difference reached no statistical significance (Table 2) $(\mathrm{P}=0.121)$.

By the types of the authors' affiliations, the rate of publication was $40.5 \%(418 / 1,033)$ for the presentations from teaching hospitals, $45.8 \%$ (22/48) for those from both teaching hospitals and private clinics, and $15.8 \%$ (15/95) for those from private clinics. These results indicate that the rate of publication was the

\begin{tabular}{|c|c|c|c|}
\hline Year & $\begin{array}{c}\text { No. of } \\
\text { abstracts }\end{array}$ & $\begin{array}{c}\text { No. } \\
\text { published }\end{array}$ & $\begin{array}{c}\text { Publication } \\
\text { rate }(\%)\end{array}$ \\
\hline 2005 (58th) & 170 & 63 & 37.1 \\
\hline 2005 (59th) & 205 & 88 & 42.9 \\
\hline 2006 (60th) & 178 & 71 & 39.9 \\
\hline 2006 (61st) & 188 & 67 & 35.6 \\
\hline 2007 (62nd) & 199 & 77 & 38.7 \\
\hline 2007 (63rd) & 236 & 89 & 37.7 \\
\hline Total & 1,176 & 455 & 38.7 \\
\hline
\end{tabular}

Table 2. Publication rates according to type of presentation

\begin{tabular}{|lccc|}
\hline $\begin{array}{l}\text { Type of } \\
\text { presentation }\end{array}$ & $\begin{array}{c}\text { No. of } \\
\text { abstracts }\end{array}$ & $\begin{array}{c}\text { No. } \\
\text { published }\end{array}$ & $\begin{array}{c}\text { Publication } \\
\text { rate (\%) }\end{array}$ \\
\hline Oral & 734 & 301 & 41.0 \\
$\quad$ Three minutes & 451 & 195 & 43.2 \\
Six minutes & 283 & 106 & 37.5 \\
Poster & 442 & 154 & 34.8 \\
\hline P=0.035. & & & \\
\hline
\end{tabular}

Table 3. Publication rates according to affiliation

\begin{tabular}{|lccc|}
\hline Affiliation & $\begin{array}{c}\text { No. of } \\
\text { abstracts }\end{array}$ & $\begin{array}{c}\text { No. } \\
\text { published }\end{array}$ & $\begin{array}{c}\text { Publication } \\
\text { rate (\%) }\end{array}$ \\
\hline Teaching hospital & 1,033 & 418 & 40.5 \\
Private clinics & 95 & 15 & 15.8 \\
Teaching hospital+private clinics & 48 & 22 & 45.8 \\
\hline $\mathrm{P}<0.001$. & & & \\
\hline
\end{tabular}

Table 4. Publication rates according to subspecialty

\begin{tabular}{|lccc|}
\hline Subspecialty & $\begin{array}{c}\text { No. of } \\
\text { abstracts }\end{array}$ & $\begin{array}{c}\text { No. of } \\
\text { publication }\end{array}$ & $\begin{array}{c}\text { Publication } \\
\text { rate (\%) }\end{array}$ \\
\hline Basic & 125 & 64 & 51.2 \\
Cosmetic & 162 & 53 & 32.7 \\
Congenital malformation & 103 & 43 & 41.7 \\
Hand surgery & 117 & 54 & 46.2 \\
Trauma & 122 & 42 & 34.4 \\
Tumor & 105 & 45 & 42.9 \\
\hline P=0.018. & & & \\
\hline
\end{tabular}

lowest from private clinics (Table 3) $(\mathrm{P}<0.001)$.

By the subspecialty area, the rate of publication was $51.2 \%$ for basic areas, $32.7 \%$ for cosmetic surgery, $41.7 \%$ for congenital malformation, $46.2 \%$ for hand surgery, $34.4 \%$ for trauma, and $42.9 \%$ for tumor surgery. This showed that the rate of publication was the highest in basic areas and the lowest in cosmetic surgery (Table 4) $(\mathrm{P}=0.018)$.

The mean period elapsed until publication was 15.04 months. Most of the abstracts (79.4\%) were published within two years following the presentation (Table 5). Notably, it was 13.8 months in Korean journals and 23.3 months in overseas journals. This showed that a longer time elapses until abstracts are published in overseas journals. By journal of publication, Korean journals accounted for $87.4 \%$ of total published abstracts, being the vast majority of those published. Of these, there were 295 abstracts published in Journal of the Korean Society of Plastic and Reconstructive Surgeons (present, Archives of Plastic Surgery), 38 published in the Journal of the Korean Cleft Palate-Craniofacial Association (present, Archives of Craniofacial Surgery) and 37 published in the Journal of the Korean Society for Aesthetic Plastic Surgery (present, Archives of Aesthetic Plastic Surgery) decreasing

Table 5. Publication rates classified according to time from meeting $(n=455)$

\begin{tabular}{|lc|}
\hline Time after meeting $(\mathbf{y r})$ & No. of abstracts published (\%) \\
\hline Before & $28(6.2)$ \\
Up to 1 & $221(48.6)$ \\
$1-2$ & $140(30.8)$ \\
$2-3$ & $44(9.7)$ \\
$3-4$ & $18(4.0)$ \\
Over 4 & $4(0.9)$ \\
\hline
\end{tabular}

Table 6. Distribution of publications in domestic journals $(n=398)$

\begin{tabular}{|lc|}
$\begin{array}{l}\text { Domestic journals } \\
\text { published (\%) }\end{array}$ & $\begin{array}{c}\text { No. of abstracts } \\
\text { pubs }\end{array}$ \\
\hline $\begin{array}{l}\text { Journal of the Korean Society of Plastic and } \\
\text { Reconstructive Surgeons }\end{array}$ & $385(9.6)$ \\
Journal of the Korean Cleft Palate-Craniofacial Association & $37(9.3)$ \\
Journal of the Korean Society for Aesthetic Plastic Surgery & $6(1.5)$ \\
The Journal of the Korean Microsurgical Society & $5(1.3)$ \\
Journal of the Korean Burn Society & $2(0.5)$ \\
Journal of Korean Medical Science & $2(0.5)$ \\
Journal of the Korean Society of Traumatology & $13(3.3)$ \\
Etc. a) & \\
\hline $\begin{array}{l}\text { a) Yonsei Medical Journal, Korean Journal of Otolaryngology-Head and Neck Surgery, } \\
\text { The Korean Journal of Gastrointestinal Endoscopy, Korean Journal of Dermatology, } \\
\text { Korean Journal of Wound Management Society, Journal of the Korean Surgical } \\
\text { Society, The Journal of the Korean Orthopaedic Association, Journal of Korean } \\
\text { Neurosurgical Society, Journal of the Korean Association of Oral and Maxillofacial } \\
\text { Surgeons, The Journal of Korean Academy of Rehabilitation Medicine, Hanyang } \\
\text { Journal of Medicine, The Ewha Medical Journal, The DongGuk Journal of Medicine. }\end{array}$ \\
\hline
\end{tabular}


Table 7. Distribution of publications in overseas journals

Overseas journals $(n=57)$

Journal of Craniofacial Surgery

Journal of Plastic Reconstructive \& Aesthetic Surgery

Annals of Plastic Surgery

Plastic and Reconstructive Surgery

Dermatologic Surgery

Etc. a)

a) Aesthetic Plastic Surgery, Annals of Dermatology, International Journal of Radiation Oncology Biology Physics, Journal of Reconstructive Microsurgery, Microsurgery, Scandinavian Journal of Plastic and Reconstructive Surgery and Hand Surgery, Stem Cells and Development, Thrombosis Research.

order. Abstracts were published in a total of 20 Korean journals (Table 6). Besides this, abstracts were published in a total of 57 overseas journals (12.6\%). Of these, there were 13 abstracts published in the Journal of Craniofacial Surgery, 12 published in the Journal of Plastic, Reconstructive and Aesthetic Surgery, 11 published in the Annals of Plastic Surgery, and ten published in Plastic and Reconstructive Surgery in decreasing order. In addition, abstracts were published in a total of 13 overseas journals (Table 7).

\section{DISCUSSION}

The annual scientific meeting of the Korean Society of Plastic and Reconstructive Surgeons is one of the largest meetings held in Korea in the field of plastic and reconstructive surgery. At this meeting, many novel research findings are presented.

Ideally, the presentation of research in meetings should be followed by its publication in journals. The reasons are as follows: 1 ) Key novel findings and useful information should also be made available to those who did not participate in the scientific meetings. This should also be applied to plastic surgeons who are experts in the relevant specialty areas from countries overseas. 2) Abstracts taken alone have many defects, and they are devoid of the information that is needed for evaluating validity and reliability. 3) There are many presentations at scientific meetings for which only preliminary data is included. It is therefore necessary to evaluate the additional data. According to Balasubramanian et al. [4], when abstracts were compared with full publications, there were minor inconsistencies in $86 \%$ and major ones in $69 \%$. This indicates that the data of the abstract contains much inaccuracy.

Despite these important characteristics, more than half of the abstracts presented at medical meetings were not published in journals [2]. Several reasons contribute in a complex manner, and these include a lack of time, low priority, ongoing prepara- tion, lack of funds or other resources, lack of faith in the quality of research, rejection of a submitted paper, a problematic relationship with co-authors, and the existence of other published reports $[3,5]$.

We analyzed a total of 1,176 abstracts that had been presented at meetings during a period ranging from 2005 to 2007 . This showed that the overall rate of publication was $38.7 \%$. The rate of publication was relatively lower in abstracts that had been presented at CKSPRS compared to that of previous studies. With regard to the rate of publication in journals of plastic surgery, two studies have reported that the rates of publication were $27 \%$ and $63.7 \%[6,7]$. With regard to the rate of publication in Korean journals by the medical specialty, two other studies reported that the rates of publication of podium presentations were $27.4 \%$ and $58 \%$ of the abstracts $[8,9]$.

We have speculated that the type of presentation and the authors' affiliations might affect the rate of publication. The rate of publication was $41.0 \%$ for abstracts that had been orally presented and $34.8 \%$ for those that had been presented in a poster presentation. This difference reached a statistical significance $(\mathrm{P}=0.035)$. Other studies have also shown that the rate of publication was relatively higher in abstracts that had been orally presented [2]. One reason is that both referees and presenters have a higher quality standard for presentations because oral presentations draw more attention to the research. In addition, by the types of the authors' affiliation, most of the abstracts had been presented from those who were affiliated with teaching hospitals (87.8\%). However, the rate of publication was $45.8 \%$ among the authors who were affiliated with both teaching hospitals and private hospitals and this corresponds to the highest value. This is not only because a multi-center study has a higher responsibility for publication in journals than does a single-center one but also because there are synergistic effects due to the latest updates by local practitioners and the infrastructure of teaching hospitals. Therefore, collaboration with teaching hospitals can lead to a better publication rate than does work by local practitioners alone.

We compared the rate of publication by six types of subspecialty according to the program book among abstracts that had been presented orally. It was found to be $51.2 \%$ in basic areas, being the highest rate of publication, and $32.7 \%$ in cosmetic surgery, being the lowest one. This difference reached a statistical significance $(\mathrm{P}=0.018)$. Presumably, the rate of publication might be relatively higher not only because there are almost no changes in the results of the study in the field of basic areas but also because changes in the sample size do not frequently occur in the stage of study design. In the field of cosmetic surgery, the authors can achieve their goals only with presentation at scien- 
tific meetings. Besides, it is also presumed that the level of objective indicators for confirming the surgical outcomes is relatively lower as compared with other specialty areas. In addition, a large percentage of cosmetic surgery takes place in private clinics. This seems to have close relationship with the lower publication rates overall from private clinics.

The mean length of the period elapsed until publication since the time of presentation at a meeting was 15.04 months. This was similar to in the findings of previous studies on publication in other specialty areas and for manuscripts published in overseas journals of plastic and reconstructive surgery [6-9]. In the current study, we analyzed abstracts that had been presented at meetings during a period ranging from 2005 to 2007 and then published by August of 2011. This is because the publication of abstracts is mostly determined within two to four years.

Journals of publication were mostly found to be Korean ones. Journal of the Korean Society of Plastic and Reconstructive Surgeons (present, Archives of Plastic Surgery), the official journal of the Korean Society of Plastic and Reconstructive Surgery, accounted for $74.1 \%$ of all journals of publication. Next, the Journal of the Korean Cleft Palate-Craniofacial Association (present, Archives of Craniofacial Surgery) and the Journal of the Korean Society for Aesthetic Plastic Surgery (present, Archives of Aesthetic Plastic Surgery) both of which are journals that are affiliated with the Korean Society of Plastic and Reconstructive Surgery, accounted for $9.6 \%$ and $9.3 \%$, respectively. This might be not only because we examined the meetings held by the Korean Society of Plastic and Reconstructive Surgery but also because the above journals had the highest impact factors in the field of plastic and reconstructive surgery in Korea. We have also confirmed that there were a total of 303 manuscripts published in nine Korea Citation Index (KCI) journals and 40 manuscripts published in two KCI candidate journals.

In addition, overseas journals that had a higher rate of publication include the Journal of Craniofacial Surgery, Journal of Plastic, Reconstructive and Aesthetic Surgery, Annals of Plastic Surgery and Plastic and Reconstructive Surgery. We have also confirmed that there were a total of 40 manuscripts published in 7 Science Citation Index (SCI) journals and a total of 16 manuscripts published in 5 Science Citation Index Expanded (SCIE) journals. The overall rate of publication was $12.6 \%$ in overseas journals as compared with Korean journals. This might result from limitations due to language problems [10].

There are some limitations of the current study, one of the most important of which is that we may have omitted published manuscripts in the results of the current study. We have attempted to minimize the impact of this by raising the accuracy with additional searches for the authors' affiliation. Moreover, because there might be an error due to the investigators, three independent investigators performed a review of the results. However, there is still a possibility that a selection bias might occur. To prevent this, the investigators should have confirmed whether manuscripts were actually published by directly contacting the authors or interviewing them. These methods might also have been used to analyze the reasons for non-publication of manuscripts. The second limitation of the current study is that our results might be over-estimated because there was a lack of a review of dual publication.

Finally, further studies are also warranted to examine the factors that might affect the rate of publication, and these include study design (prospective or retrospective), statistical analysis (present or absent), study outcome (positive or negative), and funding source. Besides, it is also possible to examine the consistency between the abstract and final publication and the reasons for non-publication of manuscripts that had been presented at meetings.

In conclusion, the mean rate of publication was $38.7 \%$ from the CKSPRS and the mean length of the period elapsed until the publication since the time of presentation was 15.04 months. Our results indicate that efforts to raise the rate of publication of abstracts presented at meetings would further raise the quality of research from and expand the contribution of the Korean Society of Plastic and Reconstructive Surgeons that is now making progress toward being an internationally recognized academic society.

\section{REFERENCES}

1. Castillo J, Garcia-Guasch R, Cifuentes I. Fate of abstracts from the Paris 1995 European Society of Anaesthesiologists meeting. Eur J Anaesthesiol 2002;19:888-93.

2. Scherer RW, Langenberg P, von Elm E. Full publication of results initially presented in abstracts. Cochrane Database Syst Rev 2007;(2):MR000005.

3. Weber EJ, Callaham ML, Wears RL, et al. Unpublished research from a medical specialty meeting: why investigators fail to publish. JAMA 1998;280:257-9.

4. Balasubramanian SP, Kumar ID, Wyld L, et al. Publication of surgical abstracts in full text: a retrospective cohort study. Ann R Coll Surg Engl 2006;88:57-61.

5. Sprague S, Bhandari M, Devereaux PJ, et al. Barriers to fulltext publication following presentation of abstracts at annual orthopaedic meetings. J Bone Joint Surg Am 2003;85:158-63.

6. van der Steen LP, Hage JJ, Loonen MP, et al. Full publication of papers presented at the 1995 through 1999 European Association of Plastic Surgeons annual scientific meetings: 
a systemic bibliometric analysis. Plast Reconstr Surg 2004; 114:113-20.

7. Rodriguez JL, Laskin DM. Subsequent publication of oral and maxillofacial surgery meeting abstracts. J Oral Maxillofac Surg 2012;70:1261-4.

8. Kim JO, Choi BW, Kim JH, et al. Observation analysis of Korean Society of Spine Surgery Annual Congress: (2001-05) free paper: from presentation to publication. J Korean Soc Spine Surg 2011;18:19-23.
9. Ha TH, Yoon DY, Goo DH, et al. Publication rates for abstracts presented by Korean investigators at major radiology meetings. Korean J Radiol 2008;9:303-11.

10. Man JP, Weinkauf JG, Tsang M, et al. Why do some countries publish more than others? An international comparison of research funding, English proficiency and publication output in highly ranked general medical journals. Eur J Epidemiol 2004;19:811-7. 